\title{
Horizontal and Vertical Distributions of Chromium in a Chromate Production District of South Central China
}

\author{
Bin Zhou ${ }^{1,2,3}$, Daoyou Huang ${ }^{1, *}$, Jinshui Wu ${ }^{1}$, Qihong Zhu ${ }^{1}$ and Hanhua Zhu ${ }^{1}$ \\ 1 Key Laboratory for Agro-Ecological Processes in Subtropical Region, Institute of Subtropical Agriculture, \\ Chinese Academy of Sciences, Changsha 410125, China; bzhou@isa.ac.cn (B.Z.); jswu@isa.ac.cn (J.W.); \\ qhzhu@isa.ac.cn (Q.Z.); hhzhu@isa.ac.cn (H.Z.) \\ 2 University of Chinese Academy of Sciences, Beijing 100049, China \\ 3 Yonker Environmental Protection Company, Ltd., Changsha 410330, China \\ * Correspondence: dyhuang@isa.ac.cn; Tel./Fax: +86-0731-8461-9732
}

Received: 24 February 2018; Accepted: 19 March 2018; Published: 22 March 2018

\begin{abstract}
To study the horizontal and vertical distribution of chromium $(\mathrm{Cr})$ in the soil of a chromate production site (CPS) and its nearby area (NA-CPS) in south central China, 61 profiles (depth: $14 \mathrm{~m}$ ) in the CPS and 69 samples (topsoil) were excavated following a grid-sampling method. The geographic coordinates, elevation, and types of soil layers were recorded, and the total $\mathrm{Cr}$ in the soil and the total $\mathrm{Cr}$ and $\mathrm{Cr}(\mathrm{VI})$ in the leachate of the soil and in the groundwater were determined. Migration of $\mathrm{Cr}$ in surface soils may be represented in terms of a multiple linear regression equation $\left(R^{2}\right.$ adj $\left.=0.632\right)$. Distance, elevation, and $\mathrm{pH}$ are the primary factors that influence the horizontal distribution of $\mathrm{Cr}$ content in the surface soils, while the $\mathrm{Cr}$ concentration in different soil profiles mostly obeys the positive or negative binomial distributions. For a positive distribution, the $\mathrm{Cr}$ concentration decreases with increasing depth in the $0.0-8.0 \mathrm{~m}$ soil layer, under the fixing effect of soil. However, it shows an upward trend with a depth in the 8-14 $\mathrm{m}$ soil layer under the influence of Cr-polluted phreatic water. Under a negative distribution, $\mathrm{Cr}$ content is stable in the 0-6 $\mathrm{m}$ layer because of the influence of chromite ore processing residue mixed with miscellaneous fills, but it decreases obviously in the 6-14 $\mathrm{m}$ layer under the fixing effect of soil. Similar vertical distributions were observed for $\mathrm{pH}, L_{C r}, L_{C r}{ }^{6+}$, and $P_{C r}{ }^{6+}$. The decreasing amplitude of the $\mathrm{Cr}$ concentration for binomial distributions is mainly affected by the $\mathrm{Cr}$ concentration, $\mathrm{pH}$, and $L R_{C r}$ of the soil. Moreover, $P_{C r}{ }^{6+}$ of soil increases with $\mathrm{pH}$, and the type of soil layer is the primary factor influencing $L R_{C r}$ in the soil profiles. Our results of the horizontal and vertical distributions of $\mathrm{Cr}$ could be used to guide investigations that are focused on reducing the number of samples in the horizontal and vertical directions at CPSs, and to improve risk assessments of CPSs and nearby areas.
\end{abstract}

Keywords: chromate production site; chromium; horizontal and vertical distributions

\section{Introduction}

As an important industrial metal element, chromium (Cr) is widely applied in the metallurgy, pigment production, electroplating, leather tanning, and antiseptics industries. Six million tons of chromite ore processing residues (COPRs) are generated annually during the process of chromate production in China and India [1]. The improper disposal of COPR has resulted in severe soil Cr pollution at chromate production sites (CPSs). Reports have shown that the reuse of COPR as a filling material has resulted in soil pollution by $\mathrm{Cr}(\mathrm{VI})$ at 15 sites in Glasgow (UK), where 10-m deep soil was polluted, and the highest $\mathrm{Cr}(\mathrm{VI})$ concentration was up to $16,000 \mathrm{mg} / \mathrm{kg}$ [2]. Soils and groundwater in many CPSs in China have been severely polluted by $\mathrm{Cr}(\mathrm{VI})$, because of the improper disposal of COPR [3]. $\mathrm{Cr}(\mathrm{VI})$ in CPSs can cause cancer and other genetic mutations [4]. Therefore, it is urgent to 
investigate, assess risk, and remediate the soils of abandoned CPSs, before which it is a prerequisite to understand the behaviors of $\mathrm{Cr}$, especially for its migration and distribution pattern in the soils of CPSs.

The migration and speciation transformation of $\mathrm{Cr}$ in soils will be influenced by many factors, such as the valence state of $\mathrm{Cr}$ ions, the soil $\mathrm{pH}$ and Eh values, the soil organic matter concentration, and the soil manganese dioxide concentration [5,6]. $\mathrm{Cr}$ (III) mainly exists in a cation form (e.g., $\mathrm{CrCl}_{3}$ and $\left.\mathrm{Cr}\left(\mathrm{NO}_{3}\right)_{3}\right)$, and it is prone to combine with organic ligands in soil [7]. $\mathrm{Cr}(\mathrm{VI})$ mainly exists in an anion form (e.g., $\mathrm{HCrO}^{4-}, \mathrm{Cr}_{2} \mathrm{O}_{7}{ }^{2-}$, and $\mathrm{CrO}_{4}{ }^{2-}$ ), and it can migrate easily in soil [8]. When the soil $\mathrm{pH}<6, \mathrm{Cr}(\mathrm{III})$ possesses a high migration capability; conversely, when the soil $\mathrm{pH}>6$, it is $\mathrm{Cr}(\mathrm{VI})$ in anion form that possesses high migration capability [9]. $\mathrm{The} \mathrm{Cr}(\mathrm{III})$ in soil is capable of transforming into $\mathrm{Cr}(\mathrm{VI})$ quickly under the influence of oxides, especially manganese dioxide [10]. In contrast, the $\mathrm{Cr}(\mathrm{VI})$ in soil can be reduced to $\mathrm{Cr}(\mathrm{III})$ by $\mathrm{Fe}^{2+}, \mathrm{S}^{2-}$, and soil organic matter under anaerobic conditions [11].

Previous studies have provided a scientific basis for elucidating the distribution of $\mathrm{Cr}$ pollution, and a few research studies indicated that the distance to the pollutant source and the landfill of COPR will affect the horizontal and vertical distribution of Cr in CPSs, respectively [12-14]. However, studies on the horizontal and vertical distribution patterns and influencing factors are still needed to guide the investigation and the risk assessment of CPSs.

Lots of chromate production plants in the world were constructed along the river in general, and the soil in these sites always contaminated by improper disposal of COPR. The CPS of Changsha, which is located nearby the Xiangjiang River, covered an area of approximately $76,000 \mathrm{~m}^{2}$, and the soil was contaminated by improper dispose of COPR as well. Therefore, the studies on the distribution patterns of $\mathrm{Cr}$ were conducted in the CPS of Changsha to achieve the following objectives: (1) to uncover the horizontal and vertical distribution patterns of $\mathrm{Cr}$ in a CPS based on chemical and statistical analysis; and, (2) to investigate the factors affecting the horizontal and vertical distributions and migration patterns of $\mathrm{Cr}$ in a CPS.

\section{Materials and Methods}

\subsection{Study Area}

The studied CPS is located in the valley of an industrial park in Changsha City, Hunan Province, China $\left(28^{\circ} 15^{\prime} 49^{\prime \prime}-28^{\circ} 16^{\prime} 08^{\prime \prime} \mathrm{N}, 112^{\circ} 57^{\prime} 10^{\prime \prime}-112^{\circ} 57^{\prime} 20^{\prime \prime} \mathrm{E}\right)$. Two pits remained in the CPS after the removal of 42 thousand tons of COPR: P1 (depth $=14 \mathrm{~m}$ ) and P2 (depth $=5 \mathrm{~m})$. The Xiangyue chemical plant, Changsha zinc plant, and a residential district are located near the CPS (NA-CPS) (Figure 1). The average elevations of the COPR storage area, production plant area, Xiangyue chemical plant, Changsha zinc plant, and residential district are $40 \mathrm{~m}, 40 \mathrm{~m}, 43 \mathrm{~m}, 45 \mathrm{~m}$, and $46 \mathrm{~m}$, respectively. The average elevation of NA-CPS is 3-6 $\mathrm{m}$ higher than that of the CPS (Figure 1).

The soils $(0-14 \mathrm{~m})$ in the CPS have four layers, including miscellaneous fills, clayey soil, medium-fine sand, and a gravel layer. The miscellaneous fills in the COPR storage area comprise clayey soils, COPR, and construction waste, but the soil in the production plant area does not contain COPR. Water injection and penetration tests were conducted to determine the permeability coefficient of the different soil layers. The permeability coefficient of the miscellaneous fills, clay, medium-fine sand, and gravel are $15 \mathrm{~m} /$ day, $0.086 \mathrm{~m} /$ day, $17 \mathrm{~m} /$ day, and $40 \mathrm{~m} /$ day, respectively.

The phreatic water in the medium-fine sand and gravel layers has an uneven distribution without a continuous and stable water surface during the dry season, and the water level is from $6.8-14.1 \mathrm{~m}$ at the CPS (elevation: 26.75-36.35 m). The lowest water level (31 October 2009), highest flood level (28 June 1998), and the annual mean water level of the Xiangjiang River is $24.87 \mathrm{~m}, 39.18 \mathrm{~m}$, and $29.48 \mathrm{~m}$, respectively (Wusong elevation). The wet season extends from April to September, and the groundwater consumption period often occurs within the period of October to the following March. 


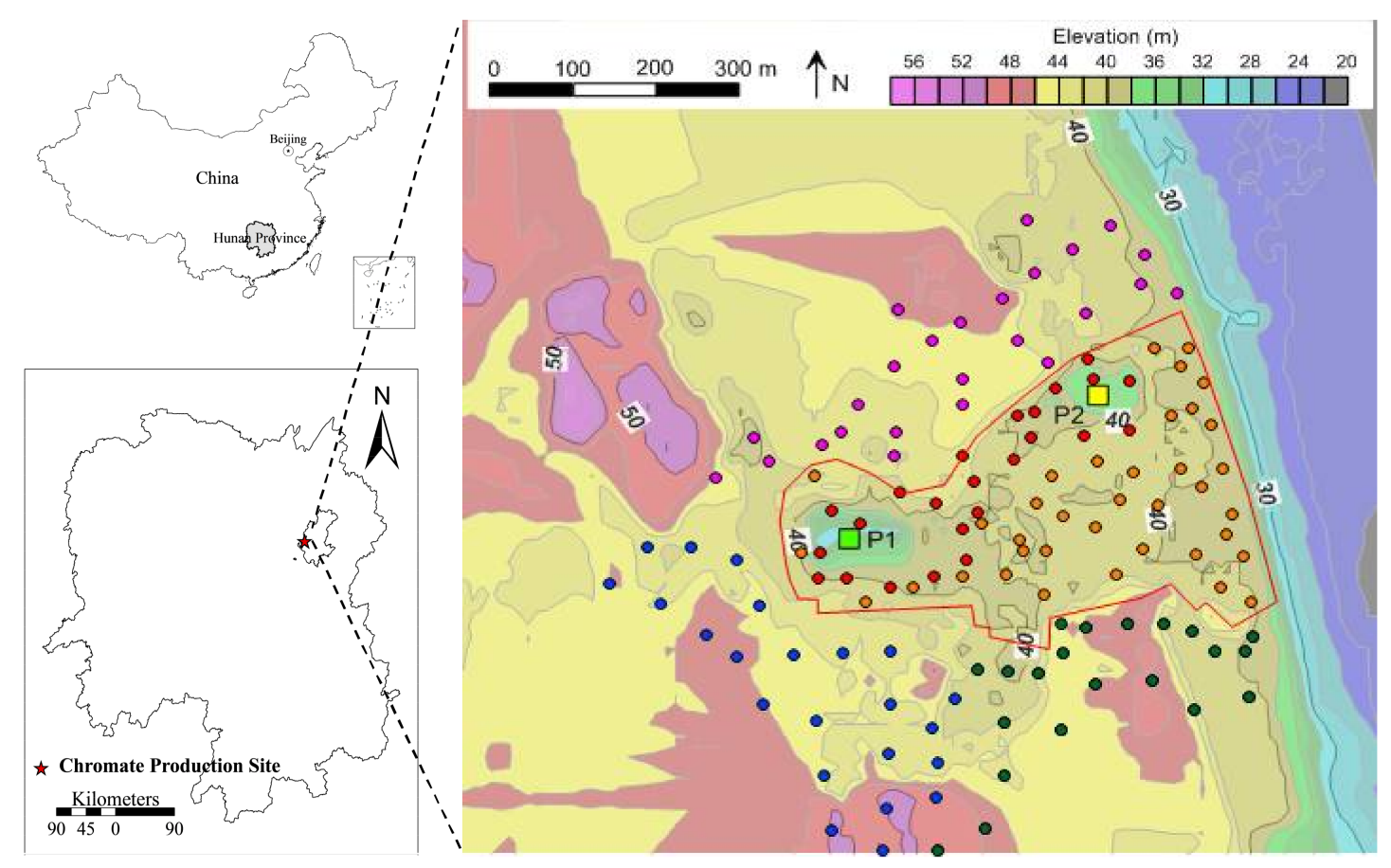

Figure 1. Location of the CPS. Red Line: boundary of the chromate production sites; Red Dots: soil profiles of the chromite ore processing residues (COPR) Storage Area; Orange Dots: soil profiles in the Production Plant Area; Pink Dots: soil profiles in the Xiangyue Chemical Plant; Green Dots: soil profiles in the Residential District; Blue Dots: soil profiles in the Changsha Zinc Plant; Square: remaining slag pits after dealing with COPR. The green and yellow squares were designated as P1 and P2, respectively.

\subsection{Soil Sampling and Analysis}

The burial depth of phreatic water in the CPS is up to $14 \mathrm{~m}$, and the soil below the phreatic water $(14 \mathrm{~m})$ mostly consists of weathered rock formations. Therefore, 61 soil profiles (depth: $14 \mathrm{~m}$ ) were excavated by Geoprobe (Model: 6620 DT; Pipe Diameter: $5 \mathrm{~cm}$ ) on a grid system at intervals of $35 \mathrm{~min}$ throughout the CPS (24 soil profiles in the COPR storage area and 37 soil profiles in the production plant area). Overall, 732 soil samples were collected at depths of $0.0-0.2,0.2-0.6,0.6-1.2,1.2-2.0$, 2.0-3.0, 3.0-4.0, 4.0-5.0, 5.0-6.0, 6.0-8.0, 8.0-10.0, 10.0-12.0, and 12.0-14.0 $\mathrm{m}$ in the CPS. In the Xiangyue chemical plant, Changsha zinc plant, and residential district, 25, 21, and 23 soil samples, respectively, were excavated at depths of $0.3-0.5 \mathrm{~m}$. In addition, According to The Technical Specification for soil Environmental monitoring (HJ/T166-2004), two background soil profiles were excavated at each of the three woodland, which are 1-1.5 km north, west, and south of CPS, respectively. Overall, 24 background soil samples were collected at depths of $0.3-0.5,3.0-3.2,6.0-6.2$, and $12.0-12.2 \mathrm{~m}$. The perched (2.0-8.0 m) and phreatic water (13.0-16.0 m) were sampled from ten profiles in the CPS for testing $\mathrm{Cr}$ and $\mathrm{Cr}(\mathrm{VI})$ concentrations. The geographic coordinate system (GCS_Beijing_1954) and elevation for each sampling point were recorded by an RTK (Zhong Haida V30, Guangzhou, China). The burial depths of the different soil layers (including miscellaneous fills, clays, medium-fine sand, and gravels) were all recorded.

The soil samples were air-dried and sieved through a 2-mm polyethylene sieve. A portion of each soil sample $(50 \mathrm{~g})$ was ground in an agate grinder and sieved through a 100 mesh-sieve in preparation for total $\mathrm{Cr}$ analysis. The soil samples were digested in groups of four with a mixture of $\mathrm{HNO}_{3}, \mathrm{HCl}, \mathrm{HF}$, and $\mathrm{HClO}_{4}$ [15]. In order to assess the leaching toxicity of $\mathrm{Cr}$ polluted soil and the toxicity and migration ability of $\mathrm{Cr}$ in the leachate under the weak acid rainfall process, the Solid waste-Extraction procedure for leaching toxicity-Sulphuric acid \& nitric acid method (SES) was used [16]. The total $\mathrm{Cr}$ concentrations in the SES leachate $\left(L_{C r}\right)$, groundwater, and the digestion 
solution were determined by Inductively Coupled Plasma Optical Emission Spectrometry (Thermo iCAP 6300, Shanghai, China). The $\mathrm{Cr}(\mathrm{VI})$ in the SES leachate $\left(\mathrm{LCr}_{\mathrm{Cr}}{ }^{6+}\right)$ and groundwater were determined by ultraviolet visible spectrophotometer (TU-1810, Beijing, China). Soil $\mathrm{pH}$ was measured in distilled water at a soil solution ratio of 1:2.5 (w/v) using a Mettler Toledo $320 \mathrm{pH}$ meter. All of the chemicals used were of guaranteed reagent grade. Blanks, $10 \%$ duplicated samples, and soil standard reference materials (Centre for Reference Materials, Beijing, China) were analyzed as part of quality assurance and quality control $(\mathrm{QA} / \mathrm{QC})$ procedures. The analyses of the recoveries for the various elements were within the range of $95-103 \%$.

\subsection{Calculations of Distance, $L R_{C r}$, and $P_{C r}{ }^{6+}$ and the Elevations of Sampling Points}

The GCS_Beijing_1954 coordinates of the central points of P1 (X=46,411.135, Y = 106,782.06) and P2 (X = 46,586.4, Y = 106,897.71) were recorded. The distances of one profile to the central points of P1 and P2 were calculated, and the distance with the smaller value was retained for subsequent analysis:

$$
\begin{aligned}
\text { Distance }=\operatorname{Min} & \left(\sqrt{\left(x_{i}-46411.14\right)^{2}+\left(y_{i}-106782.06\right)^{2}}\right. \\
& \left.: \sqrt{\left(x_{i}-46586.40\right)^{2}+\left(y_{i}-106897.71\right)^{2}}\right)
\end{aligned}
$$

where Distance refers to the minimum distance of one profile to the central points of P1 and P2, and $x_{i}$ and $y_{i}$ refer to the GCS_Beijing_1954 coordinates.

The leaching rate of soil $\mathrm{Cr}\left(L R_{C r}\right)$ can be used to describe the ratio of the easy-to-migrate $\mathrm{Cr}$ to the soil $\mathrm{Cr}$ concentration, reflecting the migratory aptitude of $\mathrm{Cr}$ in the soil. The percentage of $\mathrm{Cr}(\mathrm{VI})$ to total $\mathrm{Cr}$ in the leachate $\left(P_{\mathrm{Cr}}{ }^{6+}\right)$ reflects the toxicity and migration ability of $\mathrm{Cr}$ in the leachate, because $\mathrm{Cr}(\mathrm{VI})$ is a carcinogenic substance that is recognized by the World Health Organization, and $\mathrm{Cr}(\mathrm{VI})$ possesses higher migration capability than $\mathrm{Cr}(\mathrm{III})$ under alkaline conditions:

$$
L R_{C r}=\frac{L_{C r} \times 10}{C_{C r}} \times 100 \%
$$

where $L R_{C r}$ refers to the leaching rate of total $C r$ in the soils of the CPS and $L_{C r}$ refers to the total $C r$ concentration in the SES leachate; 10 refers to the liquid-solid ratio, according to SES, and $C_{C r}$ refers to the total $\mathrm{Cr}$ concentration in the soils.

$$
P_{C r^{6+}}=\frac{L_{C r^{6+}}}{L_{C r}} \times 100 \%
$$

where $P_{C r}{ }^{6+}$ refers to the percentage of $\mathrm{Cr}(\mathrm{VI})$ to total $\mathrm{Cr}$ in the SES leachate, $L_{C r}{ }^{6+}$ refers to the concentration of $\mathrm{Cr}(\mathrm{VI})$ in the SES leachate, and $L_{\mathrm{Cr}}$ refers to the total $\mathrm{Cr}$ concentration in the SES leachate.

\subsection{Longitudinal Distribution of $\mathrm{Cr}$ Content in Soils}

Linear, exponential, and binomial distribution functions were used to fit the $\mathrm{Cr}$ concentration to the depth for each profile in the CPS and the NA-CPS using SAS software (SAS Inst., Cary, NC, USA). The top coordinates $\left(-\frac{b}{2 a},-\frac{4 a c-b^{2}}{4 a}\right)$ of the binomial distribution functions were calculated for each soil profile in the CPS. The Cr concentration of the soil profiles obeys a positive binomial distribution (P-BD) when the parameter $a$ is greater than zero. The $\mathrm{Cr}$ concentration decreases with increasing depth in the range of $\left(0,-\frac{b}{2 a}\right) \mathrm{m}$ and increases with an increasing depth in the range of $\left(-\frac{b}{2 a}, 14\right)$ $\mathrm{m}$. The $\mathrm{Cr}$ concentration of the soil profiles obeys a negative binomial distribution (N-BD) when the parameter $a$ is smaller than zero. Finally, the $\mathrm{Cr}$ concentration increases with an increasing depth in the range of $\left(0,-\frac{b}{2 a}\right) \mathrm{m}$ and decreases with an increasing depth in the range of $\left(-\frac{b}{2 a}, 14\right) \mathrm{m}$.

$$
C_{\lg C r}=a d+b,
$$




$$
\begin{gathered}
C_{\operatorname{lgCr}}=a \exp ^{b d}+b, \\
C_{\operatorname{lgCr}}=a d^{2}+b d+c,
\end{gathered}
$$

where $C_{\lg C r}$ refers to the $\mathrm{Cr}$ concentration after a logarithmic transformation, $d$ refers to the depth of each sample central point location, and $a, b$, and $c$ are parameters with respect to the different distribution functions.

The predicted values of the $\mathrm{Cr}$ concentration were back-calculated, according to the parameters (i.e., $a, b$, and $c$ ) and depth. The values of $R^{2}$ and the root mean square error (RMSE) between the predicted and observed values of the $\mathrm{Cr}$ concentrations were calculated to assess the goodness of fit and the uncertainty of the predictions. Larger $R^{2}$ values reflect better suitability of the fitting function, and smaller values of RMSE indicate the greater reliability of the predictions:

$$
R M S E=\sqrt{\frac{1}{n} \sum_{i=1}^{n}\left[\widehat{C}_{\lg C r}\left(d_{i}\right)-C_{\operatorname{lgCr}}\left(d_{i}\right)\right]^{2}}
$$

where $\widehat{C}_{\operatorname{lgCr}}\left(d_{i}\right)$ refers to the predicted value of the Cr concentration in soils, $C_{\operatorname{lgCr}}\left(d_{i}\right)$ refers to the observed value of the $\mathrm{Cr}$ concentration in soils, and $n$ refers to the number of observed values.

\subsection{Statistical Analysis}

Microsoft Office's Excel 2010 (Microsoft Office 2010, Microsoft Corporation, Redmond, WA, USA) was used to calculate the mean values, coefficients of variation, and standard deviations. Here, a variance analysis was conducted for the data that obeyed a normal distribution. A nonparametric test was conducted for the data that disobeyed a normal distribution (Kruskal-Wallis and Mann-Whitney U). A Pearson correlation analysis and equation regression analysis were conducted using SPSS16.0 software (SPSS16.0, International Business Machines Corporation, Chicago, IL, USA) for the parameters that included elevation, distance, $\mathrm{pH}, \mathrm{Cr}$ concentration, $L_{C r}, L_{C r}{ }^{6+}, L R_{C r}$, and $P_{C r}{ }^{6+}$. In regression analysis, soil $\mathrm{Cr}$ concentration in soil was $\lg$-transformed to ensure homogeneity of variances. In addition, there are no significant differences among the different soil depths for the background values of $\mathrm{pH}, \mathrm{Cr}$ concentration, $L_{\mathrm{Cr}}$, and $\mathrm{LCr}^{6+}$. Thus, the background value indicates an average value.

\section{Results}

\subsection{General Characteristics of Surface Soils}

The average $\mathrm{pH}$ of the surface soils in the COPR storage area is 0.9 units higher than in the production plant area and 2.4-3.4 units higher than in the three NA-CPS areas (Xiangyue chemical plant, Changsha zinc plant, and the residential district). In addition, the $\mathrm{pH}$ of the NA-CPS is 1.5-2.6 units higher than the background value $(\mathrm{pH}=5.3)$ (Figure 2a). Similarly, the $\mathrm{Cr}$ concentrations, $L_{C r}, L_{C r}{ }^{6+}, P_{C r}{ }^{6+}$, and $L R_{C r}$ of the surface soils in the CPS are significantly higher than in the NA-CPS $(p<0.01)$ (Figure 2a-c). Moreover, the $\mathrm{Cr}$ concentrations, $L_{\mathrm{Cr}}, L_{\mathrm{Cr}}{ }^{6+}$, and $\mathrm{P}_{\mathrm{Cr}}{ }^{6+}$ of the surface soils in the three NA-CPS areas are similar: 2.4-5.4, 0.8-7.8, 1.5-45, and 2.0-3.4 times greater than the respective background value $\left(\mathrm{Cr}=67.8 \mathrm{mg} / \mathrm{kg}, L_{C r}=0.092 \mathrm{mg} / \mathrm{L}, L_{C r}{ }^{6+}=0.008 \mathrm{mg} / \mathrm{L}, P_{C r}{ }^{6+}=8.6 \%\right)$. The average values of the $L R_{C r}$ of the surface soils in the three NA-CPS areas are similar to the background value $\left(L R_{C r}=1.36 \%\right)$. The $\mathrm{Cr}$ concentration, $\mathrm{pH}, L_{C r}, L_{C r}{ }^{6+}, L R_{C r}$ and $P_{C r}{ }^{6+}$ of background soils have been showed as Table A1. 

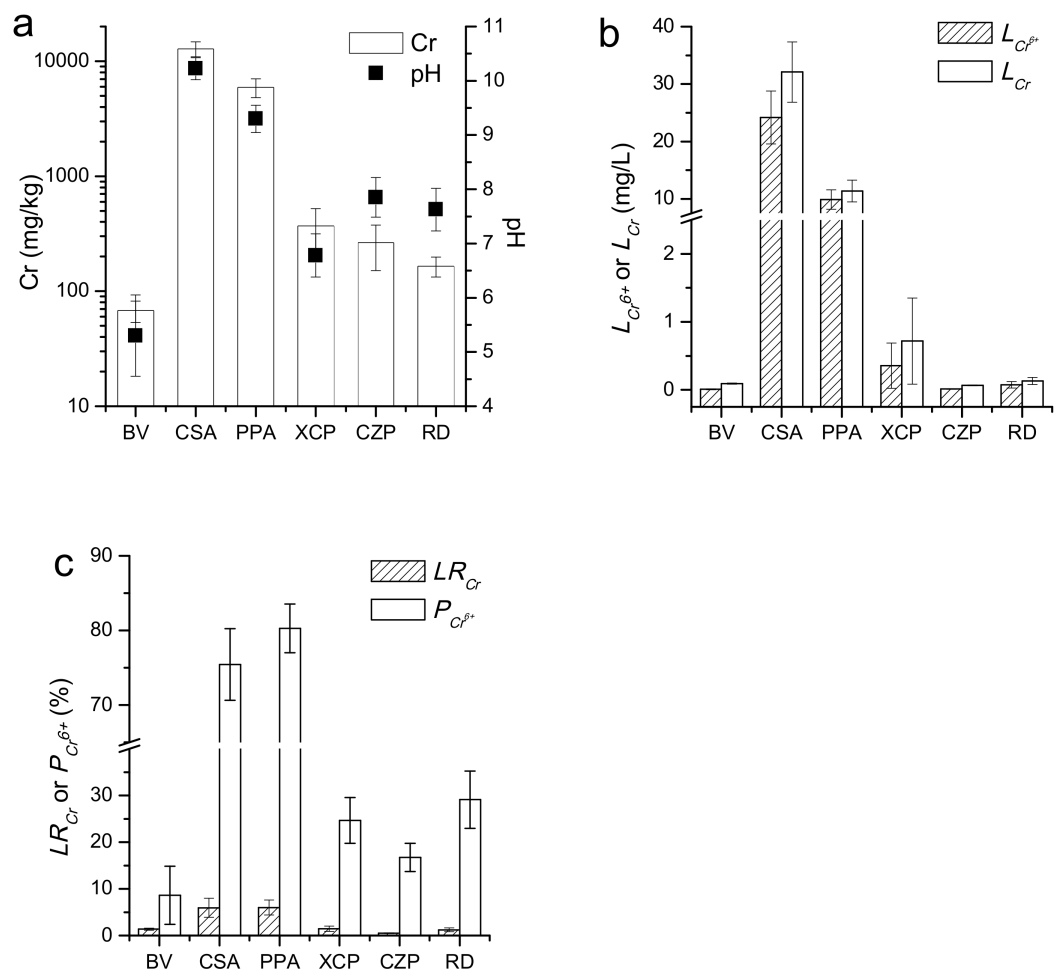

Figure 2. The $\mathrm{Cr}$ concentration and $\mathrm{pH}(\mathbf{a}), L_{C r}$ and $L_{C r}{ }^{6+}(\mathbf{b}), L_{C r}$ and $P_{C r}{ }^{6+}$ (c) of the surface soils. BV: Background Values; CSA: COPR Storage Area; PPA: Production Plant Area; XCP: Xiangyue Chemical Plant; CZP: Changsha Zinc Plant; RD: residential district.

\subsection{Distribution of $\mathrm{Cr}$ Content in Surface Soils}

Linear function fitting, exponential function fitting, and multiple linear stepwise regression analysis indicate that the distribution of the $\mathrm{Cr}$ concentration in surface soils is related to distance, elevation, and $\mathrm{pH}$ (Table 1 ). The $R^{2}$ adj values of the linear fitting equation for the $\mathrm{Cr}$ concentration to distance, elevation, and $\mathrm{pH}$ are $0.374,0.315$, and $0.451(p<0.001)$, respectively. The $R_{\text {adj }}^{2}$ values of the exponential fitting equation for the $\mathrm{Cr}$ concentration to distance, elevation, and $\mathrm{pH}$ are $0.351,0.319$, and $0.460(p<0.001)$, respectively. There is no obvious difference between the linear fitting equation and the exponential fitting equation in terms of $R^{2}$ adj. Furthermore, the multiple linear regression function, including elevation, distance, and $\mathrm{pH}$, accounts for $63.2 \%$ of the variance $\left(R^{2}\right.$ adj $\left.=0.632\right)$, and it shows predictions that are more accurate than the single-factor regression analysis.

Table 1. Fitted simple linear and exponential regressions of the value of the Cr concentration after lg-transformation $(\lg \mathrm{Cr})$ to $\mathrm{pH}$, distance, or elevation, and a summary of the multiple linear correlations between $\lg \mathrm{Cr}$ in soil and $\mathrm{pH}$, distance, and elevation in the form of $y=a+b x_{1}+c x_{2}+d x_{3}$ (stepwise regression. Criteria: probability of $\mathrm{F}$ to enter $p \leq 0.050$, probability of $\mathrm{F}$ to remove $p \geq 0.100$ ).

\begin{tabular}{cccc}
\hline Equation & $\boldsymbol{R}$ & $\boldsymbol{R}^{\mathbf{2}}$ adj & $\boldsymbol{p}^{2}$ \\
\hline $\lg \mathrm{Cr}=3.934-0.008 \times$ distance & 0.616 & 0.374 & $<0.001$ \\
$\lg \mathrm{Cr}=3.927 \times \exp (-0.003 \times$ distance $)$ & 0.598 & 0.353 & $<0.001$ \\
$\lg \mathrm{Cr}=9.403-0.155 \times$ elevation & 0.567 & 0.315 & $<0.001$ \\
$\operatorname{lgCr}=27.482 \times \exp (-0.055 \times$ elevation $)$ & 0.570 & 0.319 & $<0.001$ \\
$\lg \mathrm{Cr}=0.311+0.298 \times \mathrm{pH}$ & 0.675 & 0.451 & $<0.001$ \\
$\lg \mathrm{Cr}=1.102 \times \exp (0.106 \times \mathrm{pH})$ & 0.681 & 0.460 & $<0.001$ \\
$\lg \mathrm{Cr}=4.436+0.217 \times \mathrm{pH}-0.003 \times$ distance $-0.07 \times$ elevation & 0.800 & 0.632 & $<0.001$ \\
\hline
\end{tabular}

Chromium concentration in soil was lg-transformed to ensure homogeneity of variances. 


\subsection{Distribution of the Cr Concentration in Soil Profiles}

The vertical distribution of the Cr concentration in the CPS is simulated using linear, exponential, and binomial functions. The $R^{2}$ values $\left(R^{2}=0.743\right)$ of the binomial distribution functions are higher than those of the linear and exponential functions. Furthermore, the RMSE values $(R M S E=0.293)$ of the binomial distribution function are smaller than those of the linear and exponential functions (Table 2). This indicates that the $\mathrm{Cr}$ concentrations of the soil profiles in the study area mainly obey a binomial distribution, rather than an exponential or linear distribution. Further analysis indicates that the vertical distributions of $\mathrm{Cr}$ in the 51 soil profiles (accounting for $84 \%$ of the total profiles) of the CPS obey a binomial distribution. Twenty-nine and 22 soil profiles obey $\mathrm{P}-\mathrm{BD}\left(R^{2}=0.218, p<0.001\right)$ and N-BD $\left(R^{2}=0.208, p<0.001\right)$, respectively. Parameters $a, b$, and $c$ for the binomial distributions (P-BD and N-BD), averaged at $0.016 \pm 0.012$ and $-0.007 \pm 0.006,-0.268 \pm 0.133$ and $0.032 \pm 0.085$, and $3.973 \pm 0.597$ and $3.862 \pm 0.467$, respectively. The value of $-\frac{b}{2 a}$ for P-BD averaged at $8.4 \pm 2.2$, which indicates that the $\mathrm{Cr}$ concentration decreases with an increasing depth in the range of $0-8 \mathrm{~m}$ and increases with an increasing depth in the range of 8-14 $\mathrm{m}$. The value of $-\frac{b}{2 a}$ for N-BD is smaller than zero, which indicates that the $\mathrm{Cr}$ concentration decreases with increasing depth in the range of $0-14 \mathrm{~m}$ (Table 3).

Table 2. The $R^{2}$ and root mean square error (RMSE) values for different distribution functions.

\begin{tabular}{ccccc}
\hline Functions & Equation & $\boldsymbol{R}^{\mathbf{2}}$ & $\boldsymbol{R}^{\mathbf{2}}$ adj & $\boldsymbol{R M S E}$ \\
\hline Linear Function & Predicted $=1.197+0.649 \operatorname{lgCr}$ & 0.649 & 0.648 & 0.320 \\
Exponential Function & Predicted $=1.162+0.659 \operatorname{lgCr}$ & 0.656 & 0.655 & 0.320 \\
Binomial Distribution Function & Predicted $=0.878+0.743 \operatorname{lgCr}$ & 0.743 & 0.742 & 0.293 \\
\hline
\end{tabular}

Chromium concentration in soil was lg-transformed to ensure homogeneity of variances.

Table 3. Fitted binomial regressions of $\lg \mathrm{Cr}$ to depth $(d)$ in the form of $\left.y=a x^{2}+b x+c\right)$.

\begin{tabular}{ccc}
\hline Binomial Type & $\begin{array}{c}\text { Positive Binomial Distribution } \\
(\boldsymbol{n}=\mathbf{2 9 )}\end{array}$ & $\begin{array}{c}\text { Negative Binomial Distribution } \\
(\boldsymbol{n}=\mathbf{2 2})\end{array}$ \\
\hline$a$ & $0.016 \pm 0.012$ & $-0.007 \pm 0.006$ \\
$b$ & $-0.268 \pm 0.133$ & $0.032 \pm 0.085$ \\
$c$ & $3.973 \pm 0.597$ & $3.862 \pm 0.467$ \\
$\left(-\frac{b}{2 a},-\frac{4 a c-b^{2}}{4 a}\right)$ & $(8.4 \pm 2.2,2.7 \pm 0.4)$ & $(-2.0 \pm 4.4,4.1 \pm 0.4)$ \\
equations & $\lg \mathrm{Cr}=0.013 \times \mathrm{d}^{2}-0.026 \times \mathrm{d}+3.805$ & $\operatorname{lgCr}=-0.006 \times \mathrm{d}^{2}+0.027 \times \mathrm{d}+3.829$ \\
$R^{2}$ & 0.218 & 0.208 \\
$p$ & $<0.001$ & $<0.001$ \\
\hline
\end{tabular}

Chromium concentration in soil was lg-transformed to ensure homogeneity of variances.

\subsection{General Characteristics of Soil Profiles Obeying a Binomial Distribution}

As can be seen in Figure 3a, for the soil profiles in the CPS that obey the P-BD, the average $\mathrm{Cr}$ concentrations in the soil of the six layers at $0.0-2.0,2.0-4.0,4.0-6.0,6.0-8.0,8.0-10.0$, and 10.0-14.0 m are $9044 \pm 1468,4958 \pm 1238,2613 \pm 811,1719 \pm 623,1984 \pm 788$, and $3518 \pm 1262 \mathrm{mg} / \mathrm{kg}$, respectively. The $\mathrm{Cr}$ concentration in the soil profiles decreases significantly with increasing depth in the range of $0.0-8.0 \mathrm{~m}(p<0.01)$, but it shows an upward trend with increasing depth in the range 8.0-14.0 $\mathrm{m}$. For the soil profiles in the CPS that obey N-BD, the average $\mathrm{Cr}$ concentrations in three soil layers at $0.0-6.0,6.0-10.0$, and 10.0-14.0 $\mathrm{m}$ are $10721 \pm 1884,6960 \pm 1230$, and $3367 \pm 1166 \mathrm{mg} / \mathrm{kg}$, respectively. The $\mathrm{Cr}$ concentration is stable in the soil layer of $0.0-6.0 \mathrm{~m}$, and it decreases clearly with an increasing depth in the range of 6.0-14.0 m. In addition, there is no significant difference in the $\mathrm{Cr}$ concentrations in the layers of $0.0-2.0 \mathrm{~m}$ and 10.0-14.0 m between the soil profiles that obey the P-BD and N-BD in the CPS $(p>0.05)$. However, the Cr concentrations in the layer of $2.0-10.0 \mathrm{~m}$ in the soil profiles of the CPS that obey the P-BD are significantly lower than in the equivalent layer of the soil profiles that obey the N-BD $(p<0.01)$. 

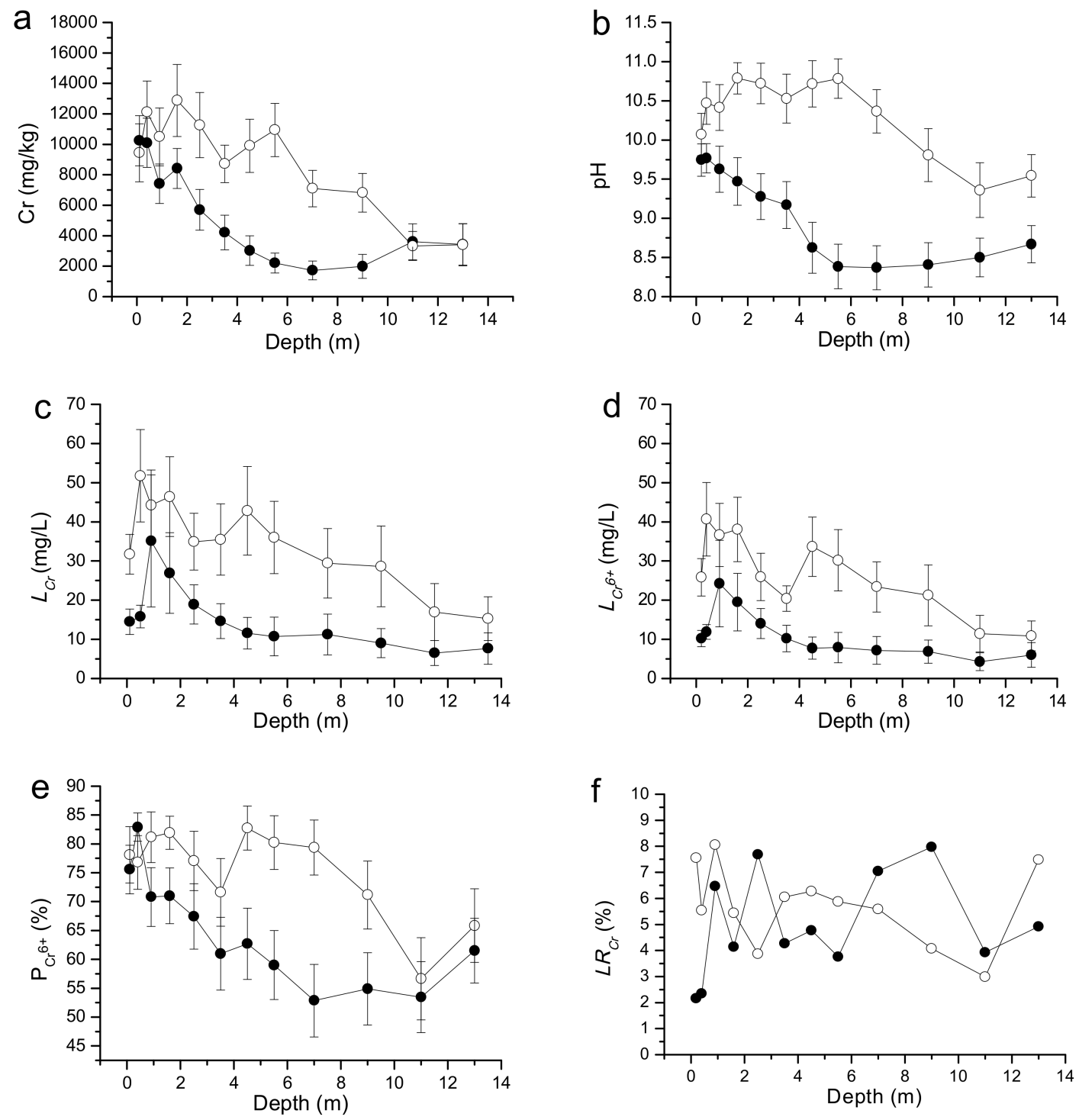

Figure 3. The Cr concentration (a), $\mathrm{pH}(\mathbf{b}), L_{C r}(\mathbf{c}), L_{C r}{ }^{6+}(\mathbf{d}), L R_{C r}(\mathbf{e})$ and $P_{C r}{ }^{6+}(\mathbf{f})$ of soil profiles that obey binomial distribution changes with depth in the chromate production sites (CPS). Solid Circle: soil profiles obey a Positive Binomial Distribution $(n=29)$; Open Circle: soil profiles obey a Negative Binomial Distribution $(n=22)$.

As can be seen in Figure $3 \mathrm{~b}-\mathrm{f}$, the $\mathrm{pH}, \mathrm{L}_{\mathrm{Cr}}, \mathrm{L}_{\mathrm{Cr}}{ }^{6+}$, and $\mathrm{P}_{\mathrm{Cr}}{ }^{6+}$ of the soil profiles that obey the P-BD in the CPS decrease significantly with an increasing depth in the range of 1.2-5.0 $\mathrm{m}(p<0.01)$, but they show no significant differences in the range of 5.0-14.0 m. To the contrary, the $\mathrm{pH}, L_{C r}, L_{C r}{ }^{6+}$, and $P_{C r}{ }^{6+}$ of the soil profiles in the CPS that obey the N-BD show no significant differences in the range of $0.0-5.0 \mathrm{~m}(p>0.05)$, but they decrease significantly with an increasing depth in the range 5.0-12.0 m. The values of $\mathrm{pH}, L_{\mathrm{Cr}}, L_{\mathrm{Cr}}{ }^{6+}$, and $P_{\mathrm{Cr}}{ }^{6+}$ of the soil profiles in the CPS that obey the N-BD are significantly higher than in the profiles that obey the P-BD $(p<0.01)$. The above analysis indicates that the $\mathrm{pH}, \mathrm{L}_{\mathrm{Cr}}, \mathrm{L}_{\mathrm{Cr}}{ }^{6+}$, and $P_{\mathrm{Cr}}{ }^{6+}$ of the soil profiles in the CPS show similar vertical distributions to $\mathrm{Cr}$. However, the $L R_{\mathrm{Cr}}$ of the soil profiles in the CPS shows no significant difference with increasing depth in the range of $0.0-14.0 \mathrm{~m}$. 


\subsection{General Characteristics of Different Soil Layers}

In order to investigate the influence of the soil layer on the migration capability of $\mathrm{Cr}$ in the soil profiles, eight profiles with clay layers in the production plant area were selected to test the $\mathrm{Cr}$ concentration, $\mathrm{pH}, L_{\mathrm{Cr}}$, and $\mathrm{LCr}_{\mathrm{Cr}}{ }^{6+}$. The $\mathrm{Cr}$ concentrations and the $\mathrm{pH}$ in the miscellaneous fill are significantly higher than those in the gravel and clay $(p<0.01)$ (Figure 4a). However, the $L_{C r}$ and $L_{C r}{ }^{6+}$ of the miscellaneous fill and the clay are significantly lower than that of the gravel $(p<0.01)$ (Figure $4 \mathrm{~b}$ ). Similar to $L_{C r}$ and $L_{C r}{ }^{6+}$, the $L R_{C r}$ values of the miscellaneous fill and the clay are also significantly lower than those of the gravel $(p<0.01)$ (Figure $4 c)$. Therefore, the type of soil layer has a significant impact on the $L R_{C r}$ in soil profiles.
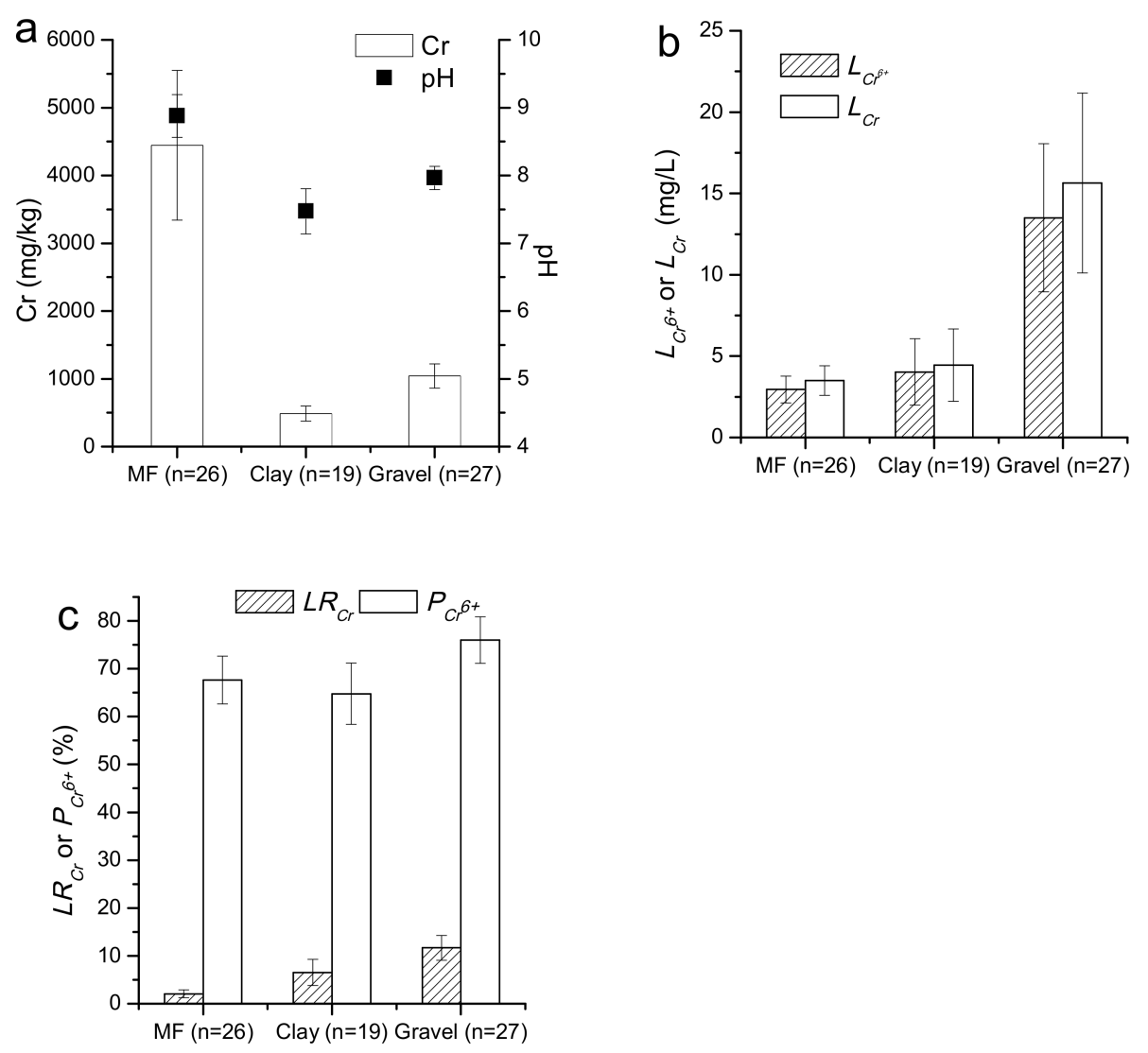

Figure 4. The $\mathrm{Cr}$ concentration and $\mathrm{pH}(\mathbf{a}), L_{C r}$ and $L_{C r}{ }^{6+}(\mathbf{b}), L R_{C r}$ and $P_{C r}{ }^{6+}$ (c) of the different soil layers. MF: Miscellaneous Fill.

\section{Discussion}

\subsection{Horizontal Distribution of $\mathrm{Cr}$ in Soil}

The distribution pattern of the $\mathrm{Cr}$ concentration in the surface soils of the study area can be represented in terms of a multiple linear regression equation $(\lg \mathrm{Cr}=4.436+0.217 \times \mathrm{pH}-0.003 \times$ distance $-0.07 \times$ elevation, $R^{2}$ adj $=0.632$ ). The COPR is the outcome of the chromate producing process, using an excessive amount of calcium oxide, sodium carbonate, and chromic iron ores via high-temperature roasting [17]. As a result, the $\mathrm{pH}$ of the COPR leachate was as high as 10-12, and the Cr concentration in the COPR reached $46 \mathrm{~g} / \mathrm{kg}[18,19]$. Over $90 \%$ of the total $\mathrm{Cr}$ exists in the form of $\mathrm{Cr}^{6+}$, when the $\mathrm{pH}$ of the leachate of COPR is above eight [20]. Therefore, the migration capability of $\mathrm{Cr}$ usually increases with a rise in $\mathrm{pH}$ [21]. This is evident by the fact that the $\mathrm{pH}$ values of the surface soils have extremely significant positive correlations with $P_{C r}{ }^{6+}(R=0.520)$ and $C r$ concentration $(R=0.526)$ (Table 4). As a result, soil $\mathrm{pH}$ could affect the distribution of the $\mathrm{Cr}$ concentration by increasing its 
migration capability. On the one hand, clay minerals, metallic oxides, and organic substances in soils are able to adsorb heavy metals that migrate in association with surface runoff [22]. On the other hand, the $\mathrm{OH}^{-}$and $\mathrm{Cr}$ in the COPR storage area and producing plant area cannot migrate to the surface soils of the NA-CPS via surface runoff, because of the effect of elevation. Therefore, the $\mathrm{Cr}$ concentrations of the surface soils have a significantly negative correlation with elevation and distance $(R=-0.523$ and -0.402 , respectively) (Table 4). A research study conducted in the CPS of Qing Hai indicated that the relationship of the $\mathrm{Cr}$ concentration with the distance to COPR can be fitted by the linear function or power function, and the power function is better than the linear function [13]. In addition, the $\mathrm{Cr}$ concentrations of the surface soils in the NA-CPS are significantly higher than the background values, indicating that the $\mathrm{Cr}$-bearing flying dust might affect the distribution of $\mathrm{Cr}$ in the surface soils of the NA-CPS. Heavy metals migration with flying dust also occurred from the activities of mining and smelting in the $\mathrm{Pb}-\mathrm{Zn}$ mine $[23,24]$. In summary, $\mathrm{pH}$, distance, and elevation are the primary factors that influence the distribution of $\mathrm{Cr}$ concentration in the surface soils.

Table 4. Pearson correlation coefficients among general characteristics of surface soils in the study area $(n=130)$.

\begin{tabular}{|c|c|c|c|c|c|c|c|}
\hline & Elevation & Distance & $\mathrm{pH}$ & $\mathrm{Cr}$ & $L_{C r}{ }^{6+}$ & $L_{C r}$ & $P_{C r}{ }^{6+}$ \\
\hline Distance & $0.607 * *$ & & & & & & \\
\hline $\mathrm{pH}$ & $-0.303^{* *}$ & $-0.394^{* *}$ & & & & & \\
\hline $\mathrm{Cr}$ & $-0.402 * *$ & $-0.523^{* *}$ & $0.526^{* *}$ & & & & \\
\hline$L_{C r}{ }^{6+}$ & $-0.322 * *$ & $-0.454 * *$ & $0.485^{* *}$ & 0.642 ** & & & \\
\hline$L_{C r}$ & $-0.351 * *$ & $-0.489 * *$ & $0.504^{* *}$ & $0.654^{* *}$ & $0.965^{* *}$ & & \\
\hline$P_{C r}^{6+}$ & $-0.515^{* *}$ & $-0.499 * *$ & $0.520^{* *}$ & 0.501 ** & $0.525^{* *}$ & $0.466^{* *}$ & \\
\hline$L R_{C r}$ & $-0.257^{* *}$ & -0.160 & 0.100 & -0.090 & $0.282^{* *}$ & $0.273^{* *}$ & $0.356^{* *}$ \\
\hline
\end{tabular}

\subsection{Vertical Distribution of $\mathrm{Cr}$ in Soil}

Twenty-nine soil profiles $\left(y=0.013 d^{2}-0.026 d+3.805\right)$ in the CPS obey the P-BD. The Cr concentrations of the profiles that obey the P-BD decrease significantly with an increasing depth in the range of $0.0-8.0 \mathrm{~m}$, but increase with increasing depth in the range of $8.0-14.0 \mathrm{~m}$. Although at least $90 \%$ of $\mathrm{Cr}(\mathrm{III})$ in the soil solution can be fixed by soil [25], only a few parts of $\mathrm{Cr}(\mathrm{VI})$ in the soil solution will be fixed by soil $[26,27]$. However, in the process of permeating to the subsoil with rainwater, the $\mathrm{Cr}(\mathrm{VI})$ can be reduced into $\mathrm{Cr}$ (III) by sulfides, ferrous iron, and soil organic matter under the condition of relatively low $\mathrm{pH}$ and $\mathrm{Eh}(-1.37 \mathrm{~V}<\mathrm{Eh}<-1.35 \mathrm{~V})[28,29]$. Therefore, the $\mathrm{Cr}$ concentration decreases with increasing depth in the range of $0.0-8.0 \mathrm{~m}$, because of the reduction and fixing effect of the soil. In addition, the values of parameter $b$ for P-BD have significant positive correlations with $L_{C r}, L_{C r}{ }^{6+}$, and $L R_{C r}$ at depths of 3-14 $\mathrm{m}(R=0.35-0.48)$, and the values of parameter $c$ for P-BD has significant positive correlations with $\mathrm{pH}$ and the concentration of $\mathrm{Cr}(R=0.35-0.91)$ at depths of $0-10 \mathrm{~m}$ (Table 5). These results indicate that the $\mathrm{Cr}$ concentration, $\mathrm{pH}$, and $L R_{C r}$ of different layers of soil will affect the decreasing amplitude of the $\mathrm{Cr}$ concentration at depths of $0-10 \mathrm{~m}$. A research study conducted on the vertical migration of $\mathrm{Cr}$ in a CPS of Chongqing City shows that the $\mathrm{Cr}$ content decreases with an increasing depth at ranges of 0-16.0 $\mathrm{m}$ at the producing plant area, COPR transfer site, and Living office area [14]. The Cr concentration of phreatic water in the CPS averaged $218 \mathrm{mg} / \mathrm{L}$, and the soil layer at depths of 10.0-14.0 $\mathrm{m}$ in the CPS is mainly composed of gravel (Figure A1), which is conducive to the migration of $\mathrm{Cr}$-polluted phreatic water [30]. As a result, the soil at depths of $10.0-14.0 \mathrm{~m}$ is contaminated by the Cr-polluted phreatic water. This can be proved by the fact that the $\mathrm{Cr}$ concentration of the soil at depths of $10.0-14.0 \mathrm{~m}$ is significantly higher than at $6.0-10.0 \mathrm{~m}$ $(p<0.01)$. A similar result has been shown by a research study on the southern area of the CPS in Chongqing City under a railway bridge in which the landfill of COPR has caused the Cr content to increase with increasing depth at ranges of 4.0-16.0 m [14]. In summary, the $\mathrm{Cr}$ concentrations in the 
soil profiles obey the P-BD because of the fixing effect of the soil and the influence of Cr-polluted phreatic water, and the decreasing amplitude of the $\mathrm{Cr}$ concentration for the $\mathrm{P}-\mathrm{BD}$ is mainly affected by the $\mathrm{Cr}$ concentration, $\mathrm{pH}$, and $L R_{\mathrm{Cr}}$ of the soil.

Twenty-two soil profiles $\left(y=-0.006 x^{2}+0.027 x+3.829\right)$ in the CPS obey the N-BD. The Cr concentration shows a stable level at soil layers at $0.0-6.0 \mathrm{~m}$, and it decreases obviously with increasing depth at ranges of $6.0-14.0 \mathrm{~m}$. This shows that the $\mathrm{Cr}$ in the subsoil at depths of $0.0-6.0 \mathrm{~m}$ comes from not only the topsoil, but also other pollutant sources, such as COPR in the miscellaneous fill. The soil layer at 0.0-6.0 $\mathrm{m}$ in the COPR storage area mainly comprises miscellaneous fills mixed with COPR (Figure A1a), and the COPR can elevate the $\mathrm{Cr}$ concentration of the surrounding soil [31]. As a result, no significant difference was found for the $\mathrm{Cr}$ concentration in the soil layer at 0.0-6.0 m. The $\mathrm{Cr}$ concentration in the soil layer at 10.0-14.0 $\mathrm{m}$ is derived not only from the $\mathrm{Cr}$ of the upper layer soil, but also from the $\mathrm{Cr}$ in the phreatic water. However, this combined effect is insufficient to elevate the Cr concentration in the soil layer at 10.0-14.0 $\mathrm{m}$ to the levels similar to or higher than the soil layer at $8.0-10.0 \mathrm{~m}$ (Figure 3a). The values of parameter $b$ for N-BD have significant positive correlations with $L_{C r}, L_{C r}{ }^{6+}$, and $L R_{C r}$ at depths of 4-14 $\mathrm{m}(R=0.47-0.62)$; the values of parameter $c$ for N-BD have positive correlations with $\mathrm{pH}$ and the concentration of $\mathrm{Cr}(R=0.19-0.92)$ at depths of $0-10 \mathrm{~m}$, and they have negative correlations with $L R_{C r}(R=-0.07-0.75)$ at depths of $0-14 \mathrm{~m}$ (Table 5). These results indicate that the $\mathrm{Cr}$ concentration, $\mathrm{pH}$, and $L R_{C r}$ in different layers of soil will affect the decreasing amplitude of the $\mathrm{Cr}$ concentration at depths of $0-14 \mathrm{~m}$. In summary, the $\mathrm{Cr}$ concentrations in the soil profiles obey the N-BD, mainly because of the influence of miscellaneous fills containing COPR and the fixing effect of the soil, and, similar to the results from the P-BD, the decreasing amplitude of the $\mathrm{Cr}$ concentration for N-BD is also mainly affected by the $\mathrm{Cr}$ concentration, $\mathrm{pH}$, and $L R_{\mathrm{Cr}}$ of the soil.

As discussed above, $\mathrm{OH}^{-}$and $\mathrm{Cr}$ share the same polluted resource, and the $P_{\mathrm{Cr}}{ }^{6+}$ usually increases with a rise in $\mathrm{pH}$. In addition, the $P_{\mathrm{Cr}}{ }^{6+}, L_{\mathrm{Cr}}$, and $L_{\mathrm{Cr}}{ }^{6+}$ have significant positive correlations with the Cr concentration ( $R=0.501-0.654)$ (Table 4). Therefore, the $\mathrm{pH}, L_{\mathrm{Cr}}, L_{\mathrm{Cr}}{ }^{6+}$, and $P_{\mathrm{Cr}}{ }^{6+}$ of the soil profiles in the CPS show similar vertical distributions to the $\mathrm{Cr}$ concentration. The $L R_{C r}$ of the soil profiles in the CPS shows no significant difference with increasing depth at ranges of $0.0-14.0 \mathrm{~m}$. This should be attributed to the fact that the $L R_{C r}$ in soil profiles is mainly affected by the type of soil layer, rather than the $\mathrm{Cr}$ concentration. The fine grains in the miscellaneous fill and clay possess higher surface activity and larger surface areas, and they comprise a greater proportion of the substance that serves to enhance the adsorption capacity of the soils [22]. As a result, the $L R_{C r}$ values of the miscellaneous fill and the clay are significantly lower than that of the gravel. Previous research has found that the vertical migration distance and the transmission rate of heavy metals in sandstone soils are far higher than in clay soils [30]. In summary, the $P_{C r}{ }^{6+}$ of soil increases with $\mathrm{pH}$, and the type of soil layer is the primary factor that influences the $L R_{C r}$ in the soil profiles. 
Table 5. The correlation coefficient of parameters to the factors of $\mathrm{pH}, \lg \mathrm{Cr}, L_{\mathrm{Cr}}, L_{\mathrm{Cr}}{ }^{6+}, P_{\mathrm{Cr}}{ }^{6+}$, and $L R_{C r}$ in the different depths of soil.

\begin{tabular}{|c|c|c|c|c|c|c|c|c|c|c|c|c|c|}
\hline \multirow{2}{*}{ Parameter } & \multirow{2}{*}{ Depth (m) } & \multicolumn{6}{|c|}{ P-BD $(n=29)$} & \multicolumn{6}{|c|}{ N-BD $(n=22)$} \\
\hline & & $\mathrm{pH}$ & $L_{C r}{ }^{6+}$ & $L_{C r}$ & $P_{C r}{ }^{6+}$ & $L R_{C r}$ & $\operatorname{lgCr}$ & $\mathrm{pH}$ & $L_{C r}{ }^{6+}$ & $L_{C r}$ & $P_{C r}{ }^{6+}$ & $L R_{C r}$ & $\operatorname{lgCr}$ \\
\hline \multirow{12}{*}{$b$} & $0.0-0.2$ & 0.07 & 0.15 & 0.16 & -0.12 & 0.32 & -0.35 & -0.16 & -0.45 * & $-0.48 *$ & 0.01 & 0.28 & -0.38 \\
\hline & $0.2-0.6$ & -0.14 & -0.15 & -0.07 & -0.07 & 0.22 & -0.43 * & -0.04 & -0.23 & -0.21 & 0.07 & $0.58^{* *}$ & $-0.60^{* *}$ \\
\hline & $0.6-1.2$ & -0.18 & 0.30 & 0.29 & -0.06 & 0.34 & -0.3 & 0.02 & $-0.45 *$ & $-0.41 *$ & -0.26 & -0.16 & -0.53 * \\
\hline & $1.2-2.0$ & -0.07 & 0.25 & 0.26 & -0.10 & 0.31 & -0.44 * & -0.20 & -0.18 & -0.09 & $-0.52 *$ & $0.65^{* *}$ & $-0.63^{* *}$ \\
\hline & $2.0-3.0$ & -0.13 & 0.22 & 0.24 & 0.02 & 0.27 & -0.14 & -0.37 & 0.12 & 0.07 & -0.01 & $0.49 *$ & -0.34 \\
\hline & $3.0-4.0$ & -0.13 & 0.37 * & 0.34 & 0.26 & 0.47 * & 0.04 & -0.3 & 0.18 & 0.39 & -0.09 & 0.54 * & -0.13 \\
\hline & $4.0-5.0$ & -0.09 & 0.40 * & 0.40 * & 0.23 & 0.48 * & 0.06 & -0.26 & $0.58^{* *}$ & $0.57^{* *}$ & 0.10 & $0.56^{* *}$ & -0.14 \\
\hline & $5.0-6.0$ & -0.01 & 0.39 * & $0.38^{*}$ & $0.59^{* *}$ & 0.48 * & 0.28 & -0.27 & $0.58^{* *}$ & $0.62 * *$ & -0.38 & 0.37 & -0.03 \\
\hline & $6.0-8.0$ & -0.02 & $0.41 *$ & $0.40 *$ & $0.38^{*}$ & 0.33 & 0.21 & 0.16 & $0.47^{*}$ & 0.48 * & -0.42 & 0.26 & 0.10 \\
\hline & $8.0-10.0$ & -0.33 & $0.42 *$ & 0.43 * & 0.11 & 0.33 & -0.10 & 0.21 & $0.56^{* *}$ & 0.53 * & 0.06 & $0.62 * *$ & -0.13 \\
\hline & $10.0-12.0$ & -0.24 & 0.35 * & 0.38 * & -0.02 & 0.35 * & -0.02 & 0.26 & 0.47 * & 0.47 * & 0.41 & 0.30 & 0.09 \\
\hline & $12.0-14.0$ & -0.28 & 0.38 * & $0.38^{*}$ & 0.26 & 0.39 * & -0.02 & -0.17 & $0.58^{* *}$ & $0.57^{* *}$ & 0.40 & $0.56^{* *}$ & 0.06 \\
\hline \multirow{12}{*}{$C$} & $0.0-0.2$ & 0.35 * & $0.41 *$ & 0.28 & $0.56^{* *}$ & -0.08 & $0.69^{* *}$ & $0.47^{*}$ & $0.57^{* *}$ & $0.63^{* *}$ & -0.11 & -0.36 & 0.54 * \\
\hline & $0.2-0.6$ & $0.59^{* *}$ & 0.47 * & $0.42 *$ & 0.07 & -0.03 & $0.88^{* *}$ & $0.46^{*}$ & 0.44 * & $0.45^{*}$ & -0.27 & $-0.70^{* *}$ & $0.92^{* *}$ \\
\hline & $0.6-1.2$ & $0.57^{* *}$ & 0.13 & 0.12 & $0.56^{* *}$ & -0.05 & $0.91^{* *}$ & 0.44 * & $0.62^{* *}$ & 0.62 ** & 0.02 & -0.07 & $0.80^{* *}$ \\
\hline & $1.2-2.0$ & 0.50 ** & 0.08 & 0.06 & 0.30 & -0.03 & $0.85^{* *}$ & $0.67^{* *}$ & 0.40 & 0.37 & 0.34 & $-0.64^{* *}$ & $0.84^{* *}$ \\
\hline & $2.0-3.0$ & 0.71 ** & 0.29 & 0.28 & 0.34 & 0.09 & $0.73^{* *}$ & $0.80 * *$ & 0.25 & 0.35 & -0.14 & $-0.60 * *$ & $0.82^{* *}$ \\
\hline & $3.0-4.0$ & $0.73^{* *}$ & 0.19 & 0.19 & -0.06 & -0.23 & $0.60 * *$ & $0.71^{* *}$ & -0.07 & -0.03 & -0.13 & $-0.74^{* *}$ & $0.71^{* *}$ \\
\hline & $4.0-5.0$ & $0.55^{* *}$ & 0.06 & 0.04 & -0.03 & -0.13 & $0.56^{* *}$ & $0.63^{* *}$ & -0.30 & -0.23 & -0.13 & $-0.75^{* *}$ & 0.60 ** \\
\hline & $5.0-6.0$ & 0.56 ** & 0.01 & 0.01 & -0.01 & -0.13 & 0.43 * & $0.64^{* *}$ & -0.52 * & $-0.58^{* *}$ & 0.26 & $-0.74^{* *}$ & $0.57^{\text {** }}$ \\
\hline & $6.0-8.0$ & 0.53 ** & 0.01 & 0.01 & -0.13 & -0.04 & 0.19 & 0.31 & -0.15 & -0.15 & 0.20 & -0.28 & 0.27 \\
\hline & $8.0-10.0$ & $0.59^{* *}$ & -0.05 & -0.04 & 0.02 & -0.09 & 0.30 & 0.01 & -0.30 & -0.27 & 0.17 & $-0.60^{* *}$ & $0.45^{*}$ \\
\hline & $10.0-12.0$ & 0.38 * & -0.06 & -0.03 & -0.12 & -0.27 & 0.41 * & -0.07 & -0.17 & -0.15 & -0.25 & -0.10 & 0.15 \\
\hline & $12.0-14.0$ & 0.32 & -0.07 & -0.08 & -0.25 & -0.15 & 0.03 & 0.31 & -0.38 & -0.29 & -0.41 & -0.51 * & 0.25 \\
\hline
\end{tabular}

${ }^{*}$ Correlation is significant at the 0.05 level (two-tailed); ** Correlation is significant at the 0.01 level (two-tailed). 


\section{Conclusions}

The studied CPS was seriously contaminated by $\mathrm{Cr}$, and the NA-CPS was also contaminated by $\mathrm{Cr}$. The migration of $\mathrm{Cr}$ in the surface soils of the study area can be represented in terms of a multiple linear regression equation $\left(R^{2}\right.$ adj $\left.=0.632\right)$. Distance, elevation, and $\mathrm{pH}$ are the primary factors that influence the horizontal distribution of the $\mathrm{Cr}$ concentration in the surface soils.

The subsoil (up to $14 \mathrm{~m}$ ) and groundwater in the CPS were also seriously contaminated by Cr. A binomial distribution function is suitable for representing the vertical distributions of $\mathrm{Cr}$ in the soil profiles of the study area. The $\mathrm{Cr}$ concentrations in the soil profiles obey the P-BD because of the fixing effect of the soil and the influence of $\mathrm{Cr}$-polluted phreatic water. The $\mathrm{Cr}$ concentrations in the soil profiles that obey the N-BD exist mainly because of the influence of miscellaneous fills containing COPR and the fixing effect of the soil. The decreasing amplitude of the $\mathrm{Cr}$ concentration for binomial distributions is mainly affected by the $\mathrm{Cr}$ concentration, $\mathrm{pH}$, and the leaching rate of $\mathrm{Cr}$ in the soil. The $\mathrm{pH}, \mathrm{L}_{\mathrm{Cr}}{ }^{6+}$, and $\mathrm{P}_{\mathrm{Cr}}{ }^{6+}$ of the soil profiles show similar vertical distributions to the $\mathrm{Cr}$ concentration. The migration capability of $\mathrm{Cr}$ in soil profiles is mainly affected by $\mathrm{pH}$ and soil type. Our results suggest that the horizontal and vertical distributions of $\mathrm{Cr}$ in a chromate production district could be used to guide the investigation and risk assessment of a CPS.

Acknowledgments: This work was supported by the National Key Technologies R \& D Program of China (2015BAD05B02), Earmarked fund for China Agriculture Research System (CARS-16-E09), and Public Service Technology Center, Institute of Subtropical Agriculture, Chinese Academy of Sciences. We would like to thank Editage [www.editage.cn] for English language editing.

Author Contributions: Daoyou Huang and Jinshui Wu conceived and designed the experiments; Bin Zhou performed the experiments; Bin Zhou and Qihong Zhu analyzed the data; Hanhua Zhu contributed reagents/materials/analysis tools; Bin Zhou wrote the paper.

Conflicts of Interest: The authors declare no conflict of interest.

\section{Appendix A}

a

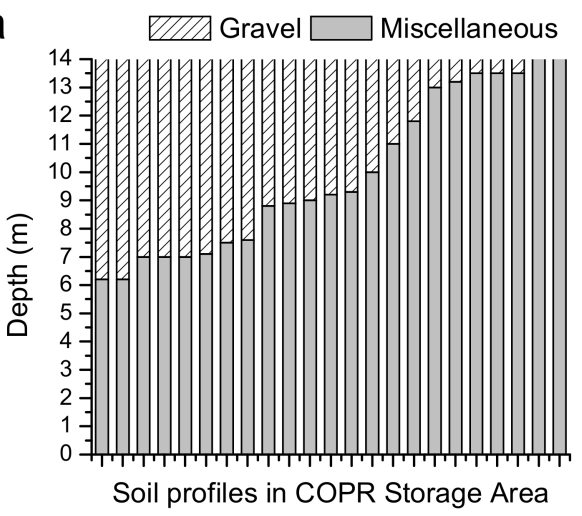

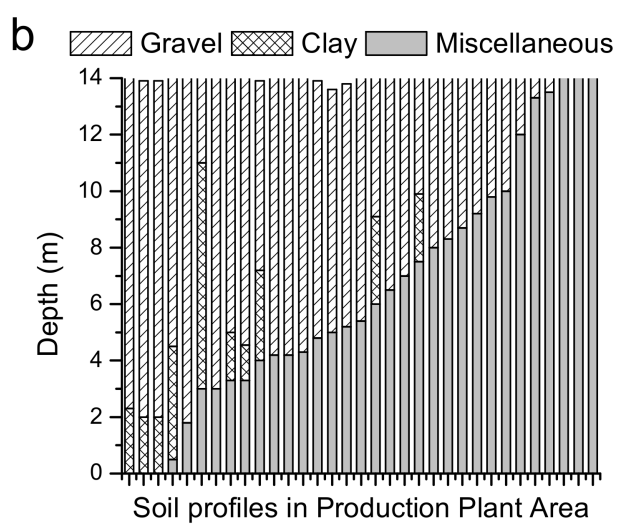

Figure A1. Soil layer structures of the soil profiles at 0-14 $\mathrm{m}$ in COPR Storage Area (a) and Prouduction Plant Area (b).

Table A1. General characteristics of background soils.

\begin{tabular}{|c|c|c|c|c|c|c|}
\hline Depth (m) & $\mathrm{pH}$ & $\mathrm{Cr}(\mathrm{mg} / \mathrm{kg})$ & $L_{C r}^{6+}(\mathrm{mg} / \mathrm{L})$ & $L_{C r}(\mathrm{mg} / \mathrm{L})$ & $L R_{C r}(\%)$ & $P_{C r}{ }^{6+}(\%)$ \\
\hline .5 & 0.7 & 11 & $0.008 \pm 0.006$ & 0.008 & $1.52 \pm 0.29$ & $8.4 \pm 6.6$ \\
\hline $3-3.2$ & $5.35 \pm 0.8$ & $64.0 \pm 11.3$ & 0.009 & 0.094 & $1.35=$ & $9.1 \pm 9.7$ \\
\hline $6-6.2$ & $5.46 \pm 1.1$ & $71.6 \pm 5.2$ & $0.006 \pm 0.003$ & $0.088 \pm 0.010$ & $1.17 \pm 0.10$ & $6.6 \pm 3.1$ \\
\hline $12-12.2$ & $5.32 \pm 0.4$ & $66.8 \pm 22.6$ & $0.010 \pm 0.004$ & $0.085 \pm 0.005$ & $1.38 \pm 0.45$ & $10.3 \pm 5.5$ \\
\hline Average values & $5.30 \pm 0.75$ & $67.8 \pm 14.4$ & $0.008 \pm 0.006$ & $0.092 \pm 0.010$ & $1.36 \pm 0.22$ & $8.6 \pm 6.24$ \\
\hline
\end{tabular}




\section{References}

1. Du, J.; Lu, J.; Wu, Q.; Jing, C. Reduction and immobilization of chromate in chromite ore processing residue with nanoscale zero-valent iron. J. Hazard. Mater. 2012, 215, 152-158. [CrossRef] [PubMed]

2. Bewley, R.J.F.; Jeffries, R.; Watson, S.; Granger, D. An overview of chromium contamination issues in the south-east of Glasgow and the potential for remediation. Environ. Geochem. Health 2001, 23, 267-271. [CrossRef]

3. Zhang, H.J.; Wang, X.R.; Chen, C.Y.; Liu, X.; Wang, Q. The Health Risk Assessmentand Remediation Guide Limitvalue of Typical Chromium Slag Contaminated Sites. Acta Sci. Circumst. 2010, 30, 1445-1450.

4. Narin, I.; Surme, Y.; Soylak, M.; Dogan, M. Speciation of $\mathrm{Cr}(\mathrm{III})$ and $\mathrm{Cr}(\mathrm{VI})$ in environmental samples by solid phase extraction on Ambersorb 563 resin. J. Hazard. Mater. 2006, 136, 579-584. [CrossRef] [PubMed]

5. Dhal, B.; Thatoi, H.N.; Das, N.N.; Pandey, B.D. Chemical and microbial remediation of hexavalent chromium from contaminated soil and mining/metallurgical solid waste: A review. J. Hazard. Mater. 2013, 250, $272-291$. [CrossRef] [PubMed]

6. Zayed, A.M.; Terry, N. Chromium in the environment: Factors affecting biological remediation. Plant Soil 2003, 249, 139-156. [CrossRef]

7. Chattopadhyay, B.; Datta, S.; Chatterjee, A.; Mukhopadhyay, S.K. The environmental impact of waste chromium of tannery agglomerates in the east Calcutta wetland ecosystem. J. Soc. Leather Technol. Chem. 2000, 84, 94-100.

8. Eary, L.E.; Davis, A. Geochemistry of an acidic chromium sulfate plume. Applied geochemistry. Appl. Geochem. 2007, 22, 357-369. [CrossRef]

9. Jean-Soro, L.; Bordas, F.; Bollinger, J.C. Column leaching of chromium and nickel from a contaminated soil using EDTA and citric acid. Environ. Pollut. 2012, 164, 175-181. [CrossRef] [PubMed]

10. Banks, M.K.; Schwab, A.P.; Henderson, C. Leaching and reduction of chromium in soil as affected by soil organic content and plants. Chemosphere 2006, 62, 255-264. [CrossRef] [PubMed]

11. Cheng, S.F.; Huang, C.Y.; Tu, Y.T.; Chen, J.R. Cr-removal efficiency as affected by the Cr-bonding fractionation in soil treated with trivalent and hexavalent chromium. Int. J. Appl. Sci. Eng. 2012, 10, 319-331.

12. Pei, T.Q.; Wang, L.; Zhong, S.; Gong, X. Pollution characteristics and treatment analysis of chromium residue and soil chromium in typical chromium residue simple stock. Chin. J. Environ. Eng. 2008, 2, 994-999. (In Chinese)

13. Luo, J.F.; Qu, D. Study on the soil Cr pollution in residue piling yard in Qinghai Province. Acta Agric. Boreali-Occident. Sin. 2006, 15, 244-247. (In Chinese)

14. Deng, H.Y. Chromium Pollution and Research on Bioremediation of Chromium Contaminated Soil in a Plant. Ph.D. Thesis, Chongqing University, Chongqing, China, 2016.

15. Cheng, J.L.; Zhou, S.H.I.; Zhu, Y.W. Assessment and mapping of environmental quality in agricultural soils of Zhejiang Province, China. J. Environ. Sci. 2007, 19, 50-54. [CrossRef]

16. Liu, F.; Wang, Q.; Huang, Q.F.; Li, L.; Zhou, D.J.; Duan, H.B.; Dai, T.Y. Study on the Standard Methods of Leaching Toxicity of Solid Waste. Res. Environ. Sci. 2008, 21, 9-15. (In Chinese)

17. Freese, K.; Miller, R.; Cutright, T.; Senko, J. Review of chromite ore processing residue (COPR): Past practices, environmental impact and potential remediation methods. Curr. Environ. Eng. 2014, 1, 82-90. [CrossRef]

18. Hillier, S.; Roe, M.J.; Geelhoed, J.S.; Fraser, A.R.; Farmer, J.G.; Paterson, E. Role of quantitative mineralogical analysis in the investigation of sites contaminated by chromite ore processing residue. Sci. Total Environ. 2003, 308, 195-210. [CrossRef]

19. Chrysochoou, M.; Dermatas, D.; Grubb, D.G.; Moon, D.H.; Christodoulatos, C. Importance of mineralogy in the geoenvironmental characterization and treatment of chromite ore processing residue. J. Geotech. Geoenviron. Eng. 2009, 136, 510-521. [CrossRef]

20. Chrysochoou, M.; Dermatas, D.; Moon, D.H.; Christodoulatos, C.; Wazne, M.; French, C.; Kaouris, M. Investigation of barium treatment of chromite ore processing residue (COPR). ASTM Int. 2006, 3. [CrossRef]

21. Zeng, F.; Ali, S.; Zhang, H.; Ouyang, Y.; Qiu, B.; Wu, F.; Zhang, G. The influence of pH and organic matter content in paddy soil on heavy metal availability and their uptake by rice plants. Environ. Pollut. 2011, 159, 84-91. [CrossRef] [PubMed]

22. Bradl, H.B. Adsorption of heavy metal ions on soils and soils constituents. J. Colloid Interface Sci. 2004, 277, 1-18. [CrossRef] [PubMed]

23. Rodríguez, L.; Ruiz, E.; Alonso-Azcárate, J.; Rincón, J. Heavy metal distribution and chemical speciation in tailings and soils around a Pb-Zn mine in Spain. J. Environ. Manag. 2009, 90, 1106-1116. [CrossRef] [PubMed] 
24. Wei, C.; Wang, C.; Yang, L. Characterizing spatial distribution and sources of heavy metals in the soils from mining-smelting activities in Shuikoushan, Hunan Province, China. J. Environ. Sci. 2009, 21, 1230-1236.

25. Ljung, K.; Otabbong, E.; Selinus, O. Natural and anthropogenic metal inputs to soils in urban Uppsala, Sweden. Environ. Geochem. Health 2006, 28, 353-364. [CrossRef] [PubMed]

26. Rock, M.L.; James, B.R.; Helz, G.R. Hydrogen peroxide effects on chromium oxidation state and solubility in four diverse, chromium-enriched soils. Environ. Sci. Technol. 2001, 35, 4054-4059. [CrossRef] [PubMed]

27. Tzou, Y.M.; Loeppert, R.H.; Wang, M.K. Light-catalyzed chromium(VI) reduction by organic compounds and soil minerals. J. Environ. Qual. 2003, 32, 2076-2084. [CrossRef] [PubMed]

28. Khérici-Bousnoubra, H.; Khérici, N.; Derradji, E.F. Behaviour of chromium VI in a multilayer aquifer in the industrial zone of Annaba, Algeria. Environ. Geol. 2009, 57, 1619-1624. [CrossRef]

29. Chrysochoou, M.; Ferreira, D.R.; Johnston, C.P. Calcium polysulfide treatment of $\mathrm{Cr}(\mathrm{VI})$-contaminated soil. J. Hazard. Mater. 2010, 179, 650-657. [CrossRef] [PubMed]

30. Maskall, J.; Whitehead, K.; Thornton, I. Heavy metal migration in soils and rocks at historical smelting sites. Environ. Geochem. Health 1995, 17, 127-138. [CrossRef] [PubMed]

31. Meegoda, J.N.; Kamolpornwijit, W.; Vaccari, D.A.; Ezeldin, A.S.; Noval, B.A.; Mueller, R.T.; Santora, S. Remediation of chromium-contaminated soils: Bench-scale investigation. Pract. Period. Hazard. Toxic Radioact. Waste Manag. 1999, 3, 124-131. [CrossRef]

(C) 2018 by the authors. Licensee MDPI, Basel, Switzerland. This article is an open access article distributed under the terms and conditions of the Creative Commons Attribution (CC BY) license (http://creativecommons.org/licenses/by/4.0/). 